\title{
LA CUESTIÓN PREJUDICIAL EN MATERIA ECONÓMICO-ADMINISTRATIVA: ¿OTRAS FORMAS DE AVANZAR EN SU PLANTEAMIENTO?
}

\author{
María Amparo Grau Ruiz \\ Catedrática de Derecho Financiero y Tributario \\ Universidad Complutense de Madrid (España) \\ Directora de la Revista Técnica Tributaria
}

Desde que el Tribunal de Justicia de la Unión Europea (en adelante, TJUE) modificó en 2020 su doctrina precedente ${ }^{1}$, los órganos de lo económico-administrativo, en su actual configuración, carecen de la habilitación para presentar cuestiones prejudiciales en los términos previstos en el artículo 267 del Tratado de Funcionamiento de la Unión Europea (en lo sucesivo, TFUE) ${ }^{2}$. Y, hasta la fecha, parece que la mera resignación sea la respuesta dada por el legislador español.
Es bien sabido que, para revertir esta situación, tales órganos necesitarían gozar de independencia. Lograrla supondría reinventarlos ${ }^{3}$, quizás en el marco de una reforma más ambiciosa de los cauces revisores en la materia. Sin entrar ahora en esta última cuestión, vale la pena dedicar estas páginas al intento de descubrir nuevas formas de «no perder una instancia» en la que se pueda «adelantar» esta petición a la institución europea, siempre que el organismo que la formule pueda

1 En la Sentencia de 21 de enero de 2020, Banco de Santander (Asunto C-274/14) [EU:C:2020:17] «Habida cuenta, en particular, de jurisprudencia más reciente del Tribunal de Justicia relativa al criterio de independencia» (apartado 55). STJUE Associaçao Sindical dos Juízes Portugueses, de 27/02/2018 [C-64/16, EU:C:2018:117, apartado 45].

2 Según el art. 267 del TFUE, el TJUE será competente para pronunciarse, con carácter prejudicial: a) sobre la interpretación de los Tratados; b) sobre la validez e interpretación de los actos adoptados por las instituciones, órganos u organismos de la Unión. Cuando se plantee una cuestión de esta naturaleza ante un órgano jurisdiccional de uno de los Estados miembros, dicho órgano podrá pedir al Tribunal que se pronuncie sobre la misma, si estima necesaria una decisión al respecto para poder emitir su fallo.

3 «Se muestra imprescindible reinventarlos, transformarlos, en el marco de una reforma global que adecue el sistema de revisión tributaria español a lo que es habitual en otros sistemas equiparables, y acorde con las exigencias del Derecho de la Unión Europea». ROZAS VALDÉS, J.A. (2020) «A propósito de "lo" económico-administrativo y de cuestiones prejudiciales», Revista Técnica Tributaria, No. 129, Sección Comentario de Jurisprudencia del TJUE. Comentario a la Sentencia del TJUE, de 21 de enero de 2020 Asunto: C-274/14 [EU:C:2020:17]. 
merecer el calificativo de órgano jurisdiccional, conforme al concepto comunitario.

Quizás la solución pase por arbitrar una colaboración más estrecha entre la vía administrativa y la contenciosa. Ésta podría suponer, tal vez, una mera modificación procedimental, o la constitución de un organismo híbrido de composición variable, a los que luego nos referiremos.

Por supuesto, en el seno de la jurisdicción contenciosoadministrativa, se da cauce, en su caso, al mecanismo de revisión prejudicial previsto en el art. 267 TFUE $^{4}$. De hecho, hay quien propugna, a la espera de una ansiada reforma, que «debería aceptarse que cuando se pone en tela de juicio la potencial vulneración del Derecho de la Unión por una disposición interna, resulta posible el acceso directo a la vía contencioso-administrativa, como en los supuestos de una eventual inconstitucionalidad de una ley. En otro caso, se produciría un claro resentimiento en otra de las garantías procesales de la tutela judicial efectiva, como es el plazo razonable de los procesos o procedimientos» ${ }^{5}$.
A nuestro juicio, el punto crítico es encontrar una solución intermedia, a mitad camino entre ambas vías, que explote las ventajas de cada una, sin dejar el menor atisbo de dudas de compatibilidad con el Derecho de la Unión Europea en su configuración y que tenga presente la dimensión temporal en la justicia.

De entrada, para hacer una relectura constructiva de la Sentencia de 21 de enero de 2020 (Asunto C-274/14), ciertamente anima tomar como punto de partida que órganos más o menos semejantes -de otros Estados miembros y dentro del nuestro- sí cuentan con aparente, real y suficiente independencia. Por ejemplo, entre los datos recogidos en la estadística judicial, se encuentran claramente diferenciadas las cuestiones planteadas por algunos órganos regionales con competencias en materia de contratación pública (como el Tribunal Català de Contractes del Sector Public o el Órgano Administrativo de Recursos Contractuales del País Vasco), junto con la Comisión Nacional de los Mercados y la Competencia, entre otros. Como se ha subrayado doctrinalmente, están legitimados a

\footnotetext{
4 «También el Tribunal Constitucional está legitimado para plantear la cuestión prejudicial. Así fue reflejado en el Auto 86/2011, de 9 de junio, en el que se hizo hincapié de su origen legal, carácter permanente, jurisdicción obligatoria, respeto del principio de contradicción, aplicación de la normativa en sus litigios, y, finalmente, su actuación independiente. También el Tribunal Supremo está legitimado para imponer la cuestión prejudicial. Asimismo, las Salas de lo ContenciosoAdministrativo de la AN y de los Tribunales Superiores de Justicia están legitimados para interponer cuestiones prejudiciales. A su vez, también los Tribunales Superiores de Justicia, los Juzgados de lo Contencioso-Administrativo, los Juzgados de lo Mercantil, los Juzgados de lo Social, la Dirección General de los Registros y del Notariado y los tribunales arbitrales son considerados órganos jurisdiccionales a efectos de plantear la cuestión prejudicial ante el TJUE». GARCÍA PRATS, F.A.; DIMITROVA SLAVCHEVA, S. (2020) Las vías de acceso a la justicia comunitaria, Sección AEDAF de Derechos y Garantías y Práctica Tributaria, pp. 18-19.

5 MULEIRO PARADA, L.M. (2020) «Los Tribunales Económico-Administrativos dejan de estar legitimados para plantear cuestiones prejudiciales: STJUE, de 21 de enero de 2020, Asunto C-274/14», Revista Aranzadi Unión Europea, No. 7 (BIB 2020\34550).
} 
La cuestión prejudicial en materia económico-administrativa: ¿otras formas de ...

plantear la cuestión prejudicial no sólo los jueces y tribunales, entendidos como poder judicial bajo el Título VI de la Constitución, sino también otro tipo de órganos internos (por ejemplo, la Dirección General de los Registros y del Notariado -ahora denominada Dirección General de Seguridad Jurídica y Fe Pública- y los tribunales arbitrales) ${ }^{6}$.

Así las cosas, es preciso detenerse a resaltar qué exigencias concretas trae consigo la determinación de la requerida independencia por el Derecho de la Unión para intentar cumplirlas en cualquier propuesta que pretenda hacerse desde España al respecto.

El TJUE diferencia el aspecto externo de la independencia judicial, relativo a la protección frente a posibles injerencias o presiones externas y la inamovilidad de sus miembros (salvo causas extraordinarias durante su mandato); del aspecto interno, referido a la imparcialidad del órgano, a modo de equidistancia respecto de las partes del procedimiento que debe resolver ${ }^{7}$.

Es fundamental la «impermeabilidad de dicho órgano frente a elementos externos y en lo que respecta a su neutralidad» 8 , que deriva básicamente de la inamovilidad y de la imparcialidad -falta de interés como parte- ${ }^{9}$.

Habría que ser especialmente cuidadosos con el nombramiento de los componentes (sin dejarlo totalmente en manos del poder ejecutivo, con el fin de obstaculizar eficazmente presiones indebidas ${ }^{10}$ ) y el cese debería estar sujeto a garantías «especiales» (superiores a las previstas por las normas generales del Derecho administrativo y del Derecho laboral). El régimen de separación tendría que estar previsto en una normativa específica, mediante disposiciones legales expresas como las aplicables a los miembros del poder judicial.

6 «Desde su jurisprudencia más temprana, el Tribunal de Justicia ha interpretado la condición de órgano jurisdiccional como un concepto amplio y autónomo, propio del Derecho de la Unión que se define por una serie de requisitos que debe reunir dicho órgano para poder reputarse 'jurisdiccional' a los efectos de plantear tal cuestión. En numerosas sentencias, como las de 30 de junio de 1966 (asunto Vaassen-Göbbels, 61/65), de 14 de diciembre de 1971 (asunto Politi, 43/71), y las recaídas en los asuntos Veuve Vaasen (61/1965), Nederlandse Spootwagen (36/1973), y Broekmeulen (246/1980), el Tribunal de Justicia ha determinado que sería órgano jurisdiccional legitimado para plantear cuestión prejudicial todo aquel que reúna supera las exigencias de origen legal, permanencia, jurisdicción obligatoria, carácter contradictorio del procedimiento, independencia y decisión en Derecho». GARCÍA PRATS, F.A.; DIMITROVA SLAVCHEVA, S., op. cit., pp. 16-17.

7 MULEIRO PARADA, L.M., op. cit., BIB $2020 \backslash 34550$.

8 Apartado 63, STJUE TDC, de 9/10/2014 [EU:C:2014:2265, apartado 29].

9 Es obvio que en el sistema vigente la composición de la Sala especial para resolver los recursos extraordinarios de unificación de doctrina (art. 243 LGT) evidencia una «confusión entre la condición de parte y la de miembro del órgano que ha de conocer el recurso» (apartado 74).

10 STJUE Syfait y otros, de 31/05/2005 [C-53/03, EU:C:2005:333, apartado 31]. 
Ahora bien, tras revisar la jurisprudencia, cabe resaltar que la inamovilidad no necesariamente ha de ser de por vida ${ }^{11}$, sino cabe limitarla al mandato temporal (como se puso de relieve en el caso Consorci Sanitari del Maresme). Además, en un órgano de composición mixta, es posible afirmarla si son inamovibles la mayoría de sus componentes ${ }^{12}$.

Es importante la calidad de tercero con respecto a la autoridad que haya adoptado la decisión recurrida (evitando cualquier confusión entre la condición de parte del procedimiento de recurso y la de miembro del órgano que ha de conocer del mismo) ${ }^{13}$.

En definitiva, a la hora de enjuiciar, los miembros habrían de ser por completo ajenos a presiones externas, directas o indirectas, del Ministerio de Hacienda. ¿Sería posible arbitrar una desvinculación orgánica y funcional? ¿En qué medida? ¿Cómo?
Desde luego, carece de sentido que la fase en vía administrativa se prolongue innecesariamente, pero demorar la búsqueda de una solución y sobrecargar la fase contenciosoadministrativa tampoco lo tiene. Conviene encontrar un equilibrio, por el bien de todos, incluido el de los contribuyentes -que a veces puede pasar desapercibido en la pugna entre poderes del Estado-.

Durante el lustro de vida del art. 237.3 de la Ley 58/2003, General Tributaria, desde que fuera introducido por el artículo único de la Ley 34/2015, de 26 de septiembre al consolidar normativamente la doctrina jurisprudencial ${ }^{14}$, el número de cuestiones prejudiciales planteadas por el Tribunal Económico Administrativo Central fue relativamente significativo, comparado con la típica inactividad de los precedentes. Así cabe apreciarlo en la siguiente tabla:

11 La inamovilidad debería limitarse a ciertos supuestos excepcionales que reflejen motivos legítimos e imperiosos que justifiquen la adopción de tal medida y en los que se respete el principio de proporcionalidad y se observen los procedimientos establecidos al efecto, como pueden ser un supuesto de incapacidad o de falta grave que les impida reunir las condiciones de aptitud para continuar en el ejercicio de sus funciones. Los apartados 11 y 20 de la Sentencia de 6 de octubre de 2015, Consorci Sanitari del Maresme (C-203/14, EU:C:2015:664) reconocen que los miembros de dicho organismo disfrutan de una garantía de inamovilidad, mientras dure su mandato, que solo admite excepciones por causas expresamente enumeradas por ley. FALCÓN Y TELLA, R. (2020) «La falta de legitimación de los Tribunales Económico-Administrativos para plantear cuestión prejudicial: TJUE 21 enero 2010», Quincena Fiscal, No. 5 (BIB 2020\8258).

12 Los apartados 29 a 31 de la Sentencia de 24 de mayo de 2016, MT Højgaard y Züblin (C-396/14, EU:C:2016:347) dejan claro que el «organismo incluye a expertos que no disfrutan de la protección particular que una disposición constitucional otorga a los magistrados, en su composición se integran asimismo magistrados que sí disfrutan de dicha protección y disponen en cualquier circunstancia de la mayoría de votos y, por tanto, de un peso preponderante en la toma de decisiones de dicho organismo, lo cual es idóneo para garantizar su independencia» [el subrayado es nuestro].

13 Cfr. Sentencias de 30 de marzo de 1993, Corbiau, C-24/92, EU:C:1993:118, apartado 15, y de 9 de octubre de 2014, TDC, C-222/13, EU:C:2014:2265, apartado 29; Sentencia de 30 de mayo de 2002, Schmid, C-516/99, EU:C:2002:313, apartados 38 a 40.

14 GARCÍA PRATS, F.A.; DIMITROVA SLAVCHEVA, S., op. cit., pp. 17-18. La reforma introduce el apartado 3 al artículo 237 que prevé el desarrollo reglamentario del procedimiento relativo a plantear 
La cuestión prejudicial en materia económico-administrativa: ¿otras formas de ...

\begin{tabular}{|l|c|c|}
\hline & 2018 & 2014 \\
\hline TEAC & 4 & 1 \\
\hline $\begin{array}{l}\text { Total } \\
\text { España }\end{array}$ & 67 & 41 \\
\hline $\begin{array}{l}\text { Total Unión } \\
\text { Europea }\end{array}$ & 568 & 428 \\
\hline $\begin{array}{l}\text { \% que } \\
\text { representa } \\
\text { España }\end{array}$ & $11,8 \%$ & $9,58 \%$ \\
\hline
\end{tabular}

Fuente: Elaboración propia a partir de los datos del TJUE

(recogidos por el Consejo General del Poder Judicial en función del tipo de órgano judicial que eleva la cuestión)

Sin embargo, a la vista de estos datos, cabe cuestionar seriamente que la mejora de la situación actual, fomentando el uso de este mecanismo europeo, pase por atribuir de algún modo naturaleza jurisdiccional -en el sentido europeo del término- a los Tribunales económicoadministrativos. Quizás, más allá de tropezar con un muro en la pretensión de lograr su eventual legitimación para plantear cuestiones de prejudicialidad conforme al art. 267 TFUE, deba la doctrina científica seguir pensando, valorando y proponiendo alternativas. También la propia Administración está llamada a realizar la oportuna evaluación normativa y adaptación de la normativa vigente a los principios de buena regulación ${ }^{15}$. Sólo con el ánimo de reabrir este debate se escriben estas líneas. Como bien decía el

cuestiones prejudiciales ante el TJUE e incorpora cuestiones procedimentales elementales: a) Se prevé el plazo de quince días para presentar alegaciones cuando el planteamiento de la cuestión prejudicial no haya sido solicitado por los interesados en la reclamación o recurso económicoadministrativo. El objeto de dichas alegaciones será exclusivamente manifestar la postura de los interesados sobre la oportunidad de plantear la cuestión prejudicial. En todo caso, el tribunal antes de plantear la cuestión prejudicial concederá un plazo de quince días a la Administración Tributaria autora del acto para que formule alegaciones. b) El órgano jurisdiccional remitente de la petición de cuestión prejudicial procederá a la suspensión de los procedimientos económico-administrativos para cuya resolución sea preciso conocer el resultado de la cuestión prejudicial planteada. Dicha decisión de suspensión se comunicará a los interesados y determinará la suspensión del cómputo del plazo de prescripción de acuerdo con el artículo 66 de la LGT. Se desarrolló el procedimiento en el art. 58 bis del Reglamento General de Revisión en vía administrativa.

15 «1. Las Administraciones Públicas revisarán periódicamente su normativa vigente para adaptarla a los principios de buena regulación y para comprobar la medida en que las normas en vigor han conseguido los objetivos previstos y si estaba justificado y correctamente cuantificado el coste y las cargas impuestas en ellas. El resultado de la evaluación se plasmará en un informe que se hará público, con el detalle, periodicidad y por el órgano que determine la normativa reguladora de la Administración correspondiente. 2. Las Administraciones Públicas promoverán la aplicación de los principios de buena regulación y cooperarán para promocionar el análisis económico en la elaboración de las normas y, en particular, para evitar la introducción de restricciones injustificadas o desproporcionadas a la actividad económica». Artículo 130 de la Ley 39/2015, de 1 de octubre, del Procedimiento Administrativo Común de las Administraciones Públicas, sobre evaluación normativa y adaptación de la normativa vigente a los principios de buena regulación. BOE núm. 236, de 02/10/2015. 
Profesor Cayón: para construir una catedral $^{16}$, empecemos con una capilla.

En su día se apuntaron varias opciones de reforma ${ }^{17}$ : 1) derogar los preceptos reguladores del planteamiento de la cuestión prejudicial en la vía económicoadministrativa; 2) modificar toda la normativa legal y reglamentaria, acerca de la designación de los miembros de los órganos económicoadministrativos y/o el recurso extraordinario para unificación de doctrina; 3) reconsiderar la obligatoriedad de la vía económicoadministrativa o, incluso, su propia configuración para convertirla en un instrumento que responda, de mejor forma, a las exigencias de las diferentes garantías procesales que delimitan el derecho a la tutela judicial efectiva. A nuestro parecer, todavía caben otras más, aunque nos puedan parecer complejas de imaginar, pero que podrían llevarse a la práctica mediante la puesta en marcha de un sistema piloto.

Sabido es que los propios tribunales deben aplicar de oficio los criterios del TJUE, o en su defecto si tienen dudas, plantear cuestiones prejudiciales. Es curioso, a la par que revelador, el análisis de la serie histórica de las cuestiones prejudiciales planteadas en lo tocante a la fiscalidad -que se refleja a continuación-.

16 En efecto, la obra de mayor envergadura pasaría por transformar los Tribunales económicoadministrativos en contencioso-tributarios, como proponía en Revista Técnica Tributaria el Profesor Rozas Valdés (2020): crear unas Oficinas de apelación en las propias Administraciones tributarias orientadas a lograr una conciliación o a preparar el posterior recurso judicial y el despliegue de una verdadera jurisdicción contencioso-tributaria, en el seno de la contencioso-administrativa, o no, que actuase en primera instancia en tribunales creados a partir de los que en la actualidad se denominan económico-administrativos, y, en segunda instancia, por apelación, ante la Audiencia Nacional (para aquellas pretensiones que se reservase un reconfigurado TEAC, como Tribunal Central de lo Contencioso Tributario), o ante los Tribunales Superiores de Justicia, para el resto. Recordaba la propuesta de convertir los tribunales económico-administrativos en una jurisdicción tributaria con competencia, también, en materia de Haciendas autonómicas y locales (Lago Montero, J.M. (2018): Litigiosidad tributaria: Estado, causas y remedios, Thomson-Reuters/Aranzadi) y el Derecho comparado en Canadá, Reino Unido, Alemania o Italia (Alonso González, L.M. y Andrés Aucejo, E. (dirs.) (2017), Resolución alternativa de conflictos (ADR) en Derecho tributario comparado, Marcial Pons).

17 MULEIRO PARADA, L.M., op. cit., BIB 2020134550. 
La cuestión prejudicial en materia económico-administrativa: ¿otras formas de ...

\begin{tabular}{|l|c|c|c|c|c|c|c|c|c|c|c|}
\hline Materia & 2020 & 2019 & 2018 & 2017 & 2016 & 2015 & 2014 & 2013 & 2012 & 2011 & 2010 \\
\hline Fiscalidad & 2 & 4 & 5 & 1 & & & & & 4 & 1 & 2 \\
\hline Total & 32 & 88 & 67 & 23 & 47 & 36 & 41 & 26 & 16 & 27 & 22 \\
\hline
\end{tabular}

\begin{tabular}{|l|c|c|c|c|c|c|c|c|c|c|}
\hline Materia & 2009 & 2008 & 2007 & 2006 & 2005 & 2004 & 2003 & 2002 & 2001 & 2000 \\
\hline Fiscalidad & 1 & 1 & 1 & 1 & & & & & & \\
\hline Total & 11 & 17 & 14 & 17 & 10 & 8 & 8 & 3 & 4 & 5 \\
\hline
\end{tabular}

Fuente: Tribunal de Justicia de la Unión Europea ${ }^{18}$

Llama la atención que, con el paso del tiempo -a lo largo de veinte años-, el número total de cuestiones prejudiciales elevadas por los jueces nacionales al Tribunal de Justicia de la Unión Europea con el fin de que resuelva dudas relativas a la aplicación de normas de Derecho Comunitario ha ido creciendo en general -pese a no ser los órganos jurisdiccionales españoles muy propensos a plantearlas-, pero esta misma tendencia no se observa en lo fiscal.

En consecuencia, puede que sea un buen momento para replantearse el diseño de un modelo organizativo acorde con las exigencias comunitarias, fundamentalmente con la tutela judicial efectiva del artículo
47 de la Carta de los derechos fundamentales de la Unión Europea (además del artículo 41 referido a la buena administración) ${ }^{19}$, de forma que se asegure la legitimidad para presentar cuestiones prejudiciales en materia fiscal ante el Tribunal de Luxemburgo.

Es muy gráfica la descripción del contenido del derecho a la tutela judicial efectiva perfilado permanentemente a través de una abundante jurisprudencia multinivel, sobre la base de garantías procesales relativas a la propia jurisdicción y el procedimiento, que no sólo comprenden la independencia y la imparcialidad, sino también un proceso en plazo razonable o sin

18 Serie por materia disponible en la página web del Consejo General del Poder Judicial https:// www.poderjudicial.es/cgpj/es/Temas/Estadistica-Judicial/Estadistica-por-temas/Aspectosinternacionales/Cuestiones-prejudiciales-iniciadas-ante-el-Tribunal-de-Justicia-de-la-UnionEuropea/ [última consulta 10 de marzo de 2021].

19 Artículo 47 de la CDFUE: «Toda persona cuyos derechos y libertades garantizados por el Derecho de la Unión hayan sido violados tiene derecho a la tutela judicial efectiva respetando las condiciones establecidas en el presente artículo. Toda persona tiene derecho a que su causa sea oída equitativa y públicamente y dentro de un plazo razonable por un juez independiente e imparcial, establecido previamente por la ley...». 
dilaciones $^{20}$. Es patente que un incumplimiento por el órgano jurisdiccional interno en cuanto al planteamiento de la cuestión prejudicial puede conculcar la tutela judicial efectiva, en su dimensión del derecho al juez predeterminado por la ley ${ }^{21}$. Otro punto que puede tomarse en consideración es que cuando el sistema de recursos diseñado dilatase en el tiempo la posibilidad de plantear la cuestión prejudicial solicitada por el contribuyente, iría en contra de la economía procesal, así como de los principios comunitarios de equivalencia y efectividad $^{22}$.

Por un lado, podría ser útil idear algún cauce procedimental para que se valore la oportunidad de plantear la cuestión prejudicial, con base en la experiencia ganada en esquemas de cooperación en otras áreas, por ejemplo, a la hora de que la administración tributaria pase el tanto de culpa a la jurisdicción penal si se observan indicios de delito.

Por otro lado, cabe traer a colación la especial configuración que en la LOPJ de 1985 se dio a las Salas de lo Civil y Penal de los Tribunales Superiores de Justicia en cuanto a las personas dotadas de potestad jurisdiccional que las integran, previendo la designación de juristas de reconocido prestigio -que ya se preveían en otros países de nuestro

20 Se delimita «el derecho a un juicio equitativo, sobre la base de unas garantías procesales relativas a la propia jurisdicción y el procedimiento y, otras, primordialmente orientadas a las partes de un proceso, para avalar la libertad frente a la actuación del poder judicial y las autoridades públicas. Entre las primeras, debemos mencionar: el derecho a un proceso público con un plazo razonable o sin dilaciones y el derecho a un Tribunal imparcial e independiente...» MULEIRO PARADA, L.M., op. cit., BIB 2020134550.

21 La STJUE de 4 de octubre de 2018, Comisión contra Francia, declara el incumplimiento del Derecho de la UE por parte de un Estado miembro que ignoró su obligación de presentar la cuestión prejudicial.

22 «Más allá de la necesaria modificación al respecto de los arts. 237.3 de la LGT y 58.bis del Real Decreto 520/2005, también se produce una restricción en el ámbito competencial de los TEA, si bien es de suma relevancia recordar que se circunscribe al examen de los actos impugnables de aplicación de las normas en vigor con independencia de la legalidad intrínseca de las mismas. Por consiguiente, la no posibilidad de plantear cuestiones prejudiciales únicamente tendrá impacto en aquellos supuestos en los que el objeto de la reclamación económico-administrativa sea la vulneración del Derecho de la UE por parte de uno de tales actos (a causa, por ejemplo, de la interpretación normativa realizada por la Administración tributaria), ya que se encuentra fuera de su competencia el control la legalidad de la normativa.

Y a tal efecto, resulta indispensable distinguir si la vulneración alegada resulta indubitada (por existir una jurisprudencia bien asentada al respecto o por no caber duda razonable alguna), puesto que sólo en el caso que sea así los TEA podrán adoptar una resolución al respecto garantizando el debido respeto del Derecho de la UE. No obstante, de no ser así, no tendrán otra opción que declararse incompetentes, ya que no podrán solicitar al TJUE que se pronuncie sobre las cuestiones prejudiciales necesarias para poder emitir su resolución.

Sin embargo, el respeto al derecho a la tutela judicial efectiva exige que, en tales casos, no se requiera el necesario agotamiento de la vía económico-administrativa y se permita el acceso directo a vía la judicial, igual que se admite cuando lo que se cuestiona es la inconstitucionalidad interna de una norma y los TEA no puedan pronunciarse al respecto ni solicitarlo al TC. Y es que, de no ser así, se estaría convirtiendo la obligación de acudir a los mismos en una demora injustificada, inútil, ineficaz y contraria a la propia economía procesal, lo mismo que ocurriría, debido a su incompetencia para valorar la legalidad intrínseca de las normas, si no se permitiera ante la potencial vulneración del Derecho de la UE por parte de una disposición interna (exigiéndolo, además, aquí los principios de equivalencia y efectividad)». ROVIRA FERRER, I. (2020) «Consecuencias de la incompetencia de los TEA para plantear cuestiones prejudiciales», Quincena Fiscal, No. 11 (BIB 2020\12188). 
La cuestión prejudicial en materia económico-administrativa: ¿otras formas de ...

entorno y que ya operaba como forma de ingreso en el Tribunal Supremo-y la participación de las asambleas legislativas autonómicas en el procedimiento a través de la presentación de una terna ${ }^{23}$. Estos magistrados/as tienen todos los derechos jurisdiccionales (independencia e inamovilidad, por ejemplo), necesarios para el ejercicio de la potestad jurisdiccional, aunque sea limitada ${ }^{24}$. Una solución similar podría buscarse en lo fiscal para que especialistas de reconocido prestigio, entre los que podría contarse con personas que hayan demostrado mérito y capacidad en los Tribunales económico-administrativos, accedieran a una Sala tributaria que dirimiese la necesidad de solicitar la pertinente aclaración europea.

De forma experimental podría pergeñarse un sistema colaborativo, combinando los diferentes márgenes de flexibilidad que ofrece el Derecho de la Unión Europea en relación con el requisito de la independencia. La mencionada Sala económico-europea, en la se concentrarían los supuestos en que se suscitase el planteamiento de una cuestión prejudicial, podría estar compuesta mayoritariamente por jueces de lo contenciosoadministrativo (contando entre ellos con la vía de acceso complementaria de expertos de reconocido prestigio), y avocarse la competencia para resolver (en caso de normas), o descentralizarla (en caso de actos). Podrían concurrir en ella todos los requisitos: 1) origen legal del órgano; 2) su permanencia; 3) el carácter obligatorio de su jurisdicción; 4) el carácter contradictorio del procedimiento; 5) la aplicación por parte del órgano de normas jurídicas; y 6) su independencia.

23 En la Exposición de Motivos se justificaba así: «incorporar a función tan relevante como la judicial a quienes, en otros campos jurídicos, han demostrado estar en condiciones de ofrecer capacidad y competencia acreditadas; por último, lograr entre la carrera judicial y el resto del universo jurídico la ósmosis que, a buen seguro, se dará cuando se integren en la judicatura quienes, por haber ejercido el Derecho en otros sectores, aportarán perspectivas diferentes e incorporarán distintas sensibilidades a un ejercicio que se caracteriza por la riqueza conceptual y la diversidad de enfoques». 24 No obstante, carecen de la mayor parte de los derechos administrativos que integran la carrera judicial, por lo que puede afirmarse que no pertenecen a la misma, pues ante ellos no existe un cursus honorum que hacer. Consejo General del Poder Judicial: Informe sobre el Anteproyecto de proposición de ley de la Asamblea de Madrid ante el Congreso de los Diputados, de modificación de la Ley Orgánica 6/1985, de 1 de julio, del Poder Judicial, y de la Ley 38/1988, de 28 de diciembre, de Demarcación y Planta Judicial, 29 de abril de 2020.

https://www.poderjudicial.es/cgpj/es/Poder-Judicial/Consejo-General-del-Poder-Judicial/Actividad-del-CGPJ/Informes/Informe-sobre-el-Anteproyecto-de-proposicion-de-ley-de-la-Asamblea-de-Madrid-ante-el-Congreso-de-los-Diputados--de-modificacion-de-la-Ley-Organica-6-1985--de-1-de-julio--del-Poder-Judicial--y-de-la-Ley-38-1988--de-28-de-diciembre--de-Demarcacion-y-Planta-Judicial [última consulta 10 de marzo de 2021]. 